\title{
APPLICATIONS OF ANTHROPOLOGY IN BUSINESS MANAGEMENT: LOCALIZATION WITH CHINESE CHARACTERISTICS
}

\author{
WEI LI \\ CENTRAL University OF FinANCE AND ECONOMICS \\ KATHY TIAN \\ LONDON SCHOOL OF ECONOMICS AND POLITICS \\ CAMILLA H. WANG \\ SHANTOU UNIVERSITY \\ YU LIU* \\ SHANTOU UNIVERSITY
}

\begin{abstract}
Management research focuses on the study of business related events and processes. It emphasizes cultural values and culturally related issues in the realm of the business world. Anthropology, as a social and behavioral science, has a unique tradition in terms of studying cultures deeply, and as such is one of the fundamental pillars of management science. Anthropological methodologies play an influential role in directing the practice of business. Having provided important guidance to the practice of business, the research methods of anthropology, especially ethnography, are now widely applied to the world of business. This paper offers an initial exploration of intrinsic relations between anthropology and business management, discusses the development and application of interdisciplinary business anthropology, and probes the pathway to localize the application of anthropology in business administration in China.
\end{abstract}

\footnotetext{
* Dr. Liu Yu is the corresponding author; he can be reached by email yliu@stu.edu.cn
} 


\section{Introduction}

At present, business administration sectors of the world are hiring employees and researchers who are knowledgeable about enterprise cultures in order to improve management as well as profitability. The environment for business is undergoing fundamental changes, and the practitioners and researchers in this field must therefore adjust themselves to these changes and utilize new approaches both in practice and in management. Although anthropology has made great contributions to the science of business management, it is a new trend in the world of business to apply the theories and methods of anthropology to the practice and research of business administration. In contrast to quantitative research methods, anthropological research, by using participant observation and in-depth interviews, can help to resolve various culture-related issues in the field of business administration. For anthropologists, administration is not only a social but also a cultural phenomenon, which is a focal point in cultural anthropology (Tian, Van Marrewijk, and Lillis 2013).

As early as in the 1920s and 1930s, a Harvard University anthropologist had embarked on the study of employee relationships and labor efficiency of the Western Electric Company located in Chicago. The principal investigators involved in the study were anthropologists. Based on anthropological research methods such as ethnographic studies using participant observation and in-depth interview, the researchers concluded that the work efficiency of employees would increase if they know the management team care about them and their work, which has influenced the study of business administration for decades. Scholars take this research as the cornerstone of the human relations school in management science (Baba, 2006).

Since then, anthropologists have begun to engage in applied research in many aspects of business management, from organizational culture studies to human resources management, product design, consumer behavior studies, competitive intelligence, and international business strategies. In 1943, the University of Chicago founded a consultancy named the Committee on Human Relations in Industry, involving applied anthropologists Burleigh Gardner, W. Lloyd Warner, and William Foote Whyte (Jacoby, 1997). Later, Gardner and Warner left the university environment and established the Social Research Cooperation Company in 1946 which became a forerunner in the field of business anthropology management consulting, successfully providing management consulting 
services to hundreds of medium-sized business companies; it still remains active today (Tian, van Marrewijk and Lillis, 2013).

The U.S. established the Research Institute for Learning in 1987 with the aim to study the natural learning process and to establish a more effective learning environment. Its main research methods are anthropological participant observation, in-depth interviews and interactive analysis. The institute's research results have been widely used in the management practice of industrial and commercial business to improve the learning ability of workers as a means to improve labor efficiency. Increasing numbers of senior management executives have recognized the contribution of business anthropologists across the country since the 1990s, making business anthropology an integral part of the academic study of business administration (Baba, 2006).

Beginning in the 1990s, throughout Europe and the United States, the effectiveness of anthropological studies for business administration, as well as anthropologists' contribution to improving the quality of business administration have been recognized widely by business leaders, which made anthropology become a new area in the study of business administration. In China, the enthusiasm for anthropological research in business is on the rise, with some market-sensitive enterprises becoming aware of the significance of anthropological studies in business and beginning to hire anthropological management staff. Some researchers have even anticipated that in the near future, many enterprises will need to prepare a new position of Chief Anthropologist to give advice to the development of enterprises (Tian and Zhou, 2012-see also Grant McCracken, 2009).

Qualitative analysis and observational studies by anthropologists can help decision-makers to improve insights, which are lacking in quantitative research. In today's business world, there is a call for cultural returns on management, and business administrators, while paying attention to turning profits, need to observe the cultural heterogeneity in enterprises through a cultural point of view to achieve a rounded enterprise development. The ethnographic study is a unique method in qualitative anthropological research, the prominent feature of which is to provide descriptive analysis that dominated in fieldwork. By observing the behavior and interactions of the people involved in management activities, anthropologists are able to better explore the significance of enterprise culture to business administration, and effectively apply it to management practices to enhance business administration efficiency and enterprise profitability. 


\section{Anthropology is a Fundamental Pillar for Business Studies}

In recent years, in Western countries with highly developed market economies, some large, multinational business firms have hired anthropologists to provide operational research for the companies' management in order to maximize profits. Some of the companies that have hired full-time anthropologists include the telecommunications equipment company Motorola, the electric appliance manufacturer General Electric, the multinational financial consortium Citibank, and the car manufacturer Toyota. Moreover, some firms, such as Microsoft and Intel, have even hired teams of anthropologists as long-term official staff within the company to engage in applied research for routine business management and for strategic development (Jordan, 2010).

Anthropological studies focus on the social and cultural environment upon which people rely for existence. In addition, these studies examine people's reactions to the environment, such as their emotions, attitudes and behaviors. The reason anthropology can be applied to the world of business administration is that the two are naturally related, and anthropology is one of the sources of management science. Put simply, anthropology is a science that studies human beings, while management is partially based on the professional knowledge of anthropology and the understanding of the effect on humanity and culture generated by anthropology. Accordingly, taking humans as the starting point, giving full play to people's initiative, and promoting the humanistic and scientific development of business administration, are no doubt an effective way to promote beneficial results for management (Hamada, 1998).

Professor Guo Yi at East China University of Science and Technology argues that because anthropology is a behavioral science that studies culture in detail, the application of anthropology in business administration, therefore, always considers some cultural factors. Instead of abstract concepts, the cultural factors in anthropology are usually comprehensible through common sense. The difference between anthropologists and nonprofessionals is that anthropologists are experts in finding "solutions" in people's daily lives, while nonprofessionals are uncritically governed by their habits formed in life, which always shape people's words and actions. In most cases, management's reactions to business issues are taken for granted without systematical thought (Guo, 2012).

In our social environment, anthropologists bring a real and unmasked attitude to communicate with their subjects of study, thus obtaining 
intuitive comprehension of beliefs, values, and fears, and hence accomplishing classic research in anthropology and ethnography (Erickson and Murphy, 2003). In the development of anthropology, there are differences in branches and directions. Taking physical anthropology and cultural anthropology as an example, the former has relatively more respect for science; the latter prefers to emphasize culture and is usually thought of as "non-scientific" by some scholars. In academia, there is always a cultural war between science and culture (Liu, 2012). If we observe the development and changes of management science from the perspective of the cultural conflict of the two, it is not hard for us to see that the theoretical development of management is pushed forward smoothly with the checks and corrections of the above two branches. Therefore, in many cases, the analysis of human beings needs to be based on the conditions of the surrounding environment. This analysis should include, without being limited to, the simple application of the generalized analytical method of natural science (Walle, 2001).

In reality, all industrial and commercial activities involve relationships among people, and as such, business administration belongs to the same category of social science as anthropology. Doctor Lv Li (Lv, 2012), one of the forerunners of the humanistic spirit in China's management science field, has pointed out that in management we can find the ideas, concepts, willpower, emotions and behaviors of the subjects, which are related to the individual but are under-determined and non-quantitative. Therefore, these non-quantitative factors are hard to objectively describe and analyze in a purely scientific manner. In other words, we can only apply qualitative methods in cultural research. In qualitative studies, the classic ethnographic research methods are closely related to traditional anthropology, and are widely used in the world of business administration. However, ethnographic studies of academic anthropology are different from those of ethnography of business administration. Apart from some differences in techniques, the differences mainly exist in their subjects of study. The subject of the former is usually non-mainstream culture, while the subject for business administrative ethnography is industrial and commercial agencies as well as their consumers and business domains. Of course, differences in research subjects have nothing to do with the adoption of specific research methods, and the special significance of anthropology to business administration lies in its unique research method of ethnography (Lan and Tian, 2011).

Unlike the research methods of many social science and management studies, the methods adopted by ethnographers are such qualitative ones as 
participant observation and the in-depth interview, while other research related to the science of management is primarily quantitative. Compared with traditional quantitative methods, qualitative methods are different but equivalent, and often flexibly applied by researchers in accordance with the changes in the environment (Walle 2002). The applicability of anthropological qualitative methods has been used in many approaches and methods in research on business administration (Walle, 2000). The discipline of business administration is in fact different from other scientific studies, especially for many aspects of enterprise cultures, because it is hard to have specific numbers for measurement, therefore it is impossible to obtain a unified answer. For this reason, more direct and more specific first-hand data is usually obtained by using participant observation and open questions. In interviews, we may encounter a wide range of questions with open answers that are both applicable and timely, and which are highly suitable for research on business administration (Tian and Dai, 2013).

In addition to involvement in human relationships, the various issues business administrations have to face are closely connected with culture, therefore can be easily resolved by anthropological theories and measures, since anthropology is one of the universally recognized areas in social and behavioral sciences which possess unique and in-depth research on culture. The practice of business administration is not only a cultural process, but also the result of cultural environmental functions. Management practice and the generation of related management patterns are in line with the evolution of cultural and ethical principles in the whole history of a specific nationality during a particular period (Lv, 2009). As the founder of anthropological fieldwork, specifically, participant observation, Malinowski put forward the principle of "getting to the heart of the local people, grasping the relationship between his attitudes and his life, so as to make clear what he thinks of the outside world" (Kardiner and Preble, 1991). Later, this research method was widely used in humanistic studies, and personally applied to management studies by Warner, who as aforementioned, pioneered the anthropological study of industrial enterprises (Tong and Yan, 2011).

Natural analysis is the core value of anthropological field investigation, and nature-oriented values and methods have made it possible for anthropology to extend its research scope continuously. In consumer behavioral studies within the science of business administration, scholars prefer "natural analysis", the basic strategy of which is to conduct research on and to explain the real-time behaviors of people through anthropological 
participant observation along with study of the cultural atmosphere and values consistent with the occurrence of these behaviors. Such a qualitative analysis has won wide acclaim for "naturalistic analysis", and the anthropological real-time participation analysis method is embodied in "naturalistic analysis" (Belk, Sherry and Wallendorf, 1989).

Ethnographic studies can reveal cultural and social patterns that are difficult to describe in the world of business administration. Dr. Kathy Rudkin and Dr. Hemant Deo of Wollongong University of Australia analyzed ethnographic methodology and its significance in research on the financial services sector. They suggested that two advantages of the ethnographic method in financial studies are worth considering. The first is that it places the researcher in actual situations to make him or her aware of the independent cultural meanings in the environment. The second is that the ethnographic method makes it possible for more researchers to pay increased attention to marginalized groups in specific social environments. Therefore, the use of the ethnographic method in the financial services sector will enable researchers to get first-hand data, which is difficult to attain by other means, and this can especially satisfy the needs of the financial services sector in terms of self-development. In other words, the ethnographic method can satisfy specific ideological and environmental demands in research on the financial services industry. There is no doubt that the results of financial services research can also be applicable to the studies of other areas in the world of business administration (Rudkin and Deo, 2006).

\section{Applications of Anthropology in Business Administration}

Anthropological theories and methods as well as the research results of anthropologists can resolve many real-time problems in the world of business administration (Jordan, 2010). There are various problems facing the world of business administration, and some problems related to the improper use of new technological tools and methods, or related to the negative work attitudes of workers. Business employees, especially those of big enterprises, with their different educational, ethnic and cultural backgrounds, need to overcome various difficulties in the creation of the cultural consistency of their organizations (Schwartz, 1991). The business administrative anthropologist can help business organizations to invest in addressing sources of difficulties and in providing solutions (Mars, 1994). 
There are not many common views concerning specific application areas of anthropology in business administration. The vitality of anthropology for business administration, however, happens to lie in the continuous development and deepening of research domains. Jordan (2010) classifies the application of anthropology in business administration into three related areas: organizational anthropology (conducting research on complicated organizations, their cultures, workflows and instructional changes), market and consumer anthropology, and design anthropology (product and service designs). Diversification and globalization are the main threads running through these research areas. Expanding on this view, some researchers have proposed that the fourth and fifth areas in business administration studies should be competitive intelligence and knowledge management (Tian, 2009) and international business or cross-cultural business communication (Ferraro, 2006). We organize these five areas into seven aspects, namely, enterprise culture, knowledge management, cultural auditing, organizational changes, product design, market research and consumer behavior, and globalization and cross-culture business (Tian and Zhou, 2012). In China, some scholars of business administration believe that the application of anthropology in business administration should be in four areas: enterprise and strategic planning, product and process design, enterprise management, and production and sales (Wang and Xu, 2012). We suggest that anthropology can play a profitable and active role in the following five major areas for business management.

\section{Auditing and Shaping Corporate Cultures}

For anthropologists, business organizations are not only economic institutions aimed at achieving profits, but are also traditional organizations which have similar research value for anthropological studies in many respects. Anthropologists do not only obtain insights into organizational culture, but can also obtain formal or informal knowledge from them (Garza, 1991). In reality, anthropologists always take the business sector as a cultural entity, which is a gathering of people whom we can apply anthropological approaches to study, to analyze, and to understand rationally. With this in mind, one should also keep in mind the related business strategic background. For example, after long-term observation and research in related business sectors, cultural anthropologist Vincent Edwards proposed the interaction model between 
enterprise behavior and social political, economic, cultural as well as natural environmental background (Edwards, V. and Lawrence, P.). The core value of the theory is the conclusion that enterprises can make use of background opportunities, and overcoming background constraints in order to promote the overall development of the enterprises (Wang and $\mathrm{Xu}, 2012)$.

In their research on social backgrounds both at home and abroad, anthropologists are especially capable of uncovering and explaining behavioral models that influence the strategies and operations of enterprises. This expertise of the anthropologists is ideal for research on how to improve business operations (Baba, 2005), using methods such as cultural auditing. In referring to a cultural audit, we refer to research on an investigation into organizational cultural features. After research on their vision, ideas, philosophy, values and relations, we can determine whether the employees consciously or unconsciously support the ideas or beliefs uncovered by the cultural auditing (Strathern, 2000). Therefore, the most important contribution from business administration anthropologists is their systematic understanding of organizational culture, their research on business strategic backgrounds, their practice of cultural auditing in business, as well as their putting forward planning and propositions for the construction of business cultural systems.

\section{Operational Management Process}

In corporate domains, anthropology is mainly involved in product design, development, and process innovation (Oliveira, 2013). An important role that the anthropologist can play in business administration is to help a business to improve capabilities in product design and development of new products, or to improve business models for promoting products to customers (Tian and Zhou, 2012). The ethnographic researcher is the best channel for product or technical designers to better understand consumer behaviors. Anthropologists usually make their observations on consumer behaviors in cultural, historical and global contexts (Jordan, 2003). When a business invites anthropologists to carry out research on new technology or methods, the management may have an opportunity to observe from a new perspective the influences of new technology on consumers.

To anthropologists, research on consumers is a social science, and consumption and the influences thereon deeply penetrate and forcefully 
influence every aspect of our lives. The value of the ethnographic research method to product development and business operation studies has been widely recognized by the business world, especially in product design domains in recent years (Squires and Byrne, 2002). For example, anthropologist Geoffrey Robinson and his colleagues applied the anthropological analysis method to observe and define the consumption process, and to help enterprises in the development and design of new products (Robinson et al, 2010). Through ethnographic studies, they not only helped to develop a new over-the-counter (OTC) medicine, but also helped a major auto manufacturer to develop a new platform truck, helped JanSport, a backpack producer, to display in a completely original way their products at a sports shop, and helped Frito-Lay to better analyze its markets. By integrating research and development and the culture, tradition, personality, and knowledge structures of engineering designers with the research results of anthropologists to promote the Research and Development(R\&D) of products and processes, we can not only satisfy the needs of current consumer groups, but we can also adjust to consumer trends and directions of the future (Garza, 1991).

\section{Business Administration and Knowledge Management}

From the historical context of business administration, we can see that the failure or success of business decision-making not only requires large quantities of data-based analysis, but also needs large amounts of non-quantitative or qualitative analysis. Therefore, the comprehensive observation of anthropologists on enterprise administration offers assistance to enterprises in reducing decision-making errors, avoiding communication barriers, and improving enterprise management efficiency. Anthropological applications in business administration lie mainly in two domains: the management of tacit knowledge, and human resources management (Tian, 2010).

In the management of knowledge systems, the concept of tacit knowledge usually refers to some individual knowledge hard to express to other members of the organization or difficult to be learned and grasped by people either within or outside the agency (Burke, 1998). The process of transforming tacit knowledge into explicit knowledge is a process of clearly expressing, managing and organizing knowledge. The findings of studies on tacit knowledge are perhaps the greatest contribution of anthropologists who serve business administration. 
The anthropological application to human resources (HR) management specifically includes the guarantee system in order to deal with issues of equity, the ways to manage staff who are too stable (or vice versa), methods to adjust the inner hierarchy of the company, or methods to react to labor disputes and other events. By way of such case study methods as participant observation and interviews, anthropologists may put forward targeted solutions to avoid excessive deviation between employee relations and organizational objectives.

\section{Marketing and Sales}

An important anthropological contribution in the marketing area is analyzing and expanding theoretical constructs concerning consumer behavior and market theories based on the experience of non-Western social research. John Sherry (1990), a leading figure of business administration anthropology, believes that there can be good cooperation between marketing and anthropology. While conducting market research, anthropologists may also analyze the symbolic meanings of products held by consumers, since this is also of great significance to the study of the motivations of consumers to improve their economic and social status, regardless of whether or not these motivations are conscious or unconscious. According to anthropological theory, the social and cultural factors of enterprises usually affect consumers. As such, the key to the success of business firms lies in the extent to which they understand the needs, desires, and enthusiasm of consumers for specific products or service, as well as in the ways to arouse such enthusiasm (Anderson, 2009; Belk, Fischer and Kozinets, 2013; Cayla and Amould 2013, 2014; Denny and Sunderland, 2014; Pedro, 2013; Sherry, 1990).

\section{International and Cross-culture Management}

With the progress of globalization and world economic integration, there is a need for many enterprises to expand their business worldwide and hence there is need for cross-cultural management. The success of international business relies heavily on effective communication under specific rules, and because of globalization, the business market environment has crossed national borders. Therefore, it is especially important for anthropologists to help with organizational inspection and to assist with the remolding of corporate value systems as well as to help 
enterprises see the world from a new perspective (Jordan, 2003). The combined efforts of anthropologists and scholars of other specializations can help enterprises in building a globalized system, signing various agreements and formalizing rules to coordinate business systems (Yucel, Elibol and Dagdelen, 2009).

Anthropologist Edward T. Hall built a career in the cross-cultural communication field and eventually wrote several seminal works about his insights from business, anthropology, communications, and other related fields. His practice and influence in the fields of cross-cultural communication and intercultural training has been monumental. He clearly understood that errors in cross-cultural communication could destroy a business deal or a peace agreement. In his book, The Silent Language, Hall explains that communication includes nonverbal characteristics and we need to understand these characteristics in the cultural context (Hall, 1981). In his later books, he explored the culturally different ways of conceiving space and time, as well as implications for business practice. Hall's practice in and theoretical contributions to business communication had great impact and international value in terms of cross-cultural factors. Anthropologists, such as Gray Ferraro among others, have continued Hall's work on communication in international settings (Ferraro, 2002).

The most famous cross-cultural business communication anthropologist Geert Hofstede (1991) has created a global model for helping business professionals to distinguish cultural differences for individual countries. This most-cited cross-cultural communication model, commonly known as the 'four dimensions of culture' model, analyzes power distance, uncertainty avoidance, individualism-collectivism, and masculinity-femininity. Many researchers such as Redpath and Nielsen (1997), Emery and Tian (2003, 2002), among others, have added one more dimension to the Hofstede model. We term this dimension as Confucian dynamism, which has the special intention of differentiating Chinese from Western cultural values. The contributions from Hofstede and his successors have played an important role in facilitating international business and cross-cultural communications.

\section{The Rise and Development of Business Anthropology}

Anthropological applications in business administration indicate the great contribution to business studies by business anthropology's unique research methods. The contribution of anthropologists to business 
administration is universal in the management world. The roles of business anthropologists, their corresponding functions and contributions, the anthropological needs of various business organizations, as well as their research achievements often benefit from the ethnographic research methods of anthropologists. Methods such as participant observation are utilized to collect necessary information, which allows anthropologists to utilize their anthropological skills and ethnographic methods to carry out research in business administration to fully realize anthropological potential, improve business performance, and increase profits.

The term "business anthropology" came into use beginning in the 1980s. We can trace the earliest business anthropology back to the European colonial period in the 19th century. An example of a company using such work is the British East India Company, which once hired anthropologists to conduct research in India in order to serve the business interests of the company (Qi, Wang, and Liu 2012). The Hawthorne Project (1924) for Western Electric is the generally accepted landmark for the appearance of anthropology in Western business. This research marks the first phase of business anthropological development. At that time, anthropologists from Harvard University carried out research on employee relationships and labor efficiency at Western Electric Company in Chicago based on the theories of the Functional School of Anthropology. The Hawthorne Project applied classic anthropological research methods such as participant observation. The researchers drew a conclusion that had a great influence on business administration studies for many decades. The researchers concluded that the labor efficiency of staff can become higher with an increase in the level of concern for staff on the part of the management (Jordan, 2010).

A second phase of applied anthropology began after World War II. The research of anthropologist Helen B. Schwartzman of Northwestern University in the United States played a significant role in the field of business anthropology. In 1941, Harvard University established the Anthropological Club, and in 1946, certain anthropological professors of Harvard University left the university to establish their own consultation company, which, as aforementioned, pioneered anthropological consultation in business administration. The business of the company included all areas and departments of business administration, and the firm successfully provided consultation services to hundreds of large and medium-sized businesses. To this day, it is still one of the most active consultation companies in business administration (Bruce, Henry and Dennison, 2006). 
The third phase in applied anthropology took place during the 1960s and 1970s. The research during this period benefited from the fieldwork of anthropologists in hetero-cultural areas. Due to the contribution of anthropological studies to politics and research ethics, governments began to pay greater attention to investment in research. At the same time, encouraging the relative independence of the research objects by anthropologists was part of this agenda. This period was also a significant period for discussion of anthropological research ethics.

The fourth phase of anthropological development was in the 1980s, during which business organizations developed great interest in anthropological research. The University of California organized the first Academic Society to conduct research on organizational culture and management, and compiled their own quarterly publications, which promoted the development of the discipline. During this period, management had developed to the point where many firms had become interested in the new stage of cultural management theory. At this time, anthropological research in business administration drew wide attention, with large numbers of enterprises beginning to hire anthropologists for the development of businesses (Tian and Zhou, 2012).

Since the mid-1990s, many anthropology departments at European and American universities have formally offered business anthropology courses, and some institutions have enrolled doctorate and postgraduate students. These universities include Michigan State University, Albany State University, North Texas State University, and Denmark's Copenhagen University among others. The Boulder Campus of Colorado State University recently began offering double majors in business administration and anthropology, which has proven to be very popular. Based on the work of Dr. Jordan, since the mid-1980s, the influence of anthropological theories and methods has grown ever larger (Jordan, 2003), especially in the courses of organizational behavior, consumer behavior, marketing and management, business competitive information and other fields. Professors in business colleges have widely introduced anthropological theories and methods in their teaching practices, and thus improved their teaching qualities and effectiveness. Dr. Michael Jordan published his seminal work Business Anthropology in 2003, which marked the formal establishment of the sub-discipline of business anthropology. At present, as an independent course, business anthropology has begun to be set up in some departments in Chinese universities.

In China's anthropological academic circles applied research, with an orientation towards government administration and towards solutions for 
practical problems, has witnessed great development (Tian and Zhou, 2012). In fact, anthropology is only a general term that encompasses all research for the solution of practical problems through anthropological methods. For example, when we apply anthropological methods in our research to solve educational problems, we call it educational anthropology. Similarly, when we use it in research to solve urban issues, we call it urban anthropology. Business anthropology is an emerging cross-discipline applying anthropological methods to business administration practice, and it belongs both to the social sciences and to management. Therefore, we can consider it as a comprehensive discipline. In Europe and the United States, ever-greater numbers of anthropologists are involved in research in business strategies and operations, and in such studies, anthropologists tend to assess product qualities and possible consumer reactions before the actual sales of the technological products begin (Tian, Van Marrewijk and Lillis, 2013).

As the economy in China evolves and changes, business strategy must also adapt. There is no doubt that the economic transition in China will affect business strategies across a wide range of industries, from telecommunications to automotive, hospitality, airlines, textiles, cosmetics, and so on (Alon, 2003; Gerth, 2010). It covers a wide range of activities, such as how to upgrade products and services to meet international market needs, how to reach the target market effectively, how to establish the positioning of products and services, and how to effectively conduct advertising and promotions internationally and cross-culturally. Chinese business leaders realize the changes taking place every day in the world marketplace. They fully understand that to better market their products and services internationally they must have a better understanding of international market environments from a cultural perspective (Paliwoda and Ryans, 2008).

\section{Localization in the Chinese Context}

Anthropology in China has always, traditionally, taken practical application as its guiding ideology, and has provided a management basis at different levels for the nation, government, and various enterprises. However, in the cultivation of modern business and administrative talent in China, there is a serious lack of related anthropological knowledge in education, to say nothing of a lack of involvement of anthropologists in the management practice of business organizations. As a result, there is a 
dearth of research results and related documents, and neither the academic world nor the business sectors know much about business anthropology. Nevertheless, in the last 30 years, the rapid development of China's business sector as well as its culture has provided very good conditions for the rise and development of business anthropology in the country.

Given the reality of the development of business anthropology in China, it is worth mentioning the study of Nongmingong (peasants who work in urban areas), a unique social and economic phenomenon in the modern Chinese business world. Dr. Zhou Daming and his students were pioneers, who studied this phenomenon beginning in the middle of 1990s. They looked at group differences among Nongmingong and suggested that business leaders must be aware of the group differences in their everyday business management operations (Zhou and Sun, 2009). Several recent endeavors are worth noting. Dr. Qi Xiaoguang applies anthropological fieldwork methods to study the issues of corporate cultures faced by international companies in China (Qi, 2011). Dr. Chen Gang uses anthropological approaches to study the tourism in Yunnan Province and suggests that the Yunnan tourism industry should mobilize local ethnic resources to develop the tourism business intensively (Bai and Chen, 2012). Dr. Wang Chunxia has shown how different religious thoughts and customs have generated various impacts on business practices in Macau Chinese business communities (Wang, 2012). Li Dekuan, an anthropological program doctoral supervisor and professor at Ningxia University, studies the significance of ethnicity in human resources management in business firms that either hire minority employees or conduct business operations in minority concentration areas (Li, 2012).

Along with accelerating industrialization and urbanization, Chinese society has undergone gradual transformation, and at the same time has witnessed a business era which is different from traditional times before the establishment of People's Republic of China. In fact, some local scholars have noticed such trends. An example is Dr. Chen Yunpiao, who once called for politicians, management experts, and anthropologists in China to face up to the coming of the business era, and to conduct research on the social-cultural changes as well as changes brought about in such areas as people's behavioral models, ways of thinking, value systems and many other aspects of culture. Chen argues that in this new era, the relationship between man and machine has become closer than in any other period in history. At the same time, the harmony and conditions of such a relationship has become one of the most important issues for all 
organizations (manufacturing organizations in particular). In this case, a worker should not only be qualified technologically, but must also adapt himself or herself to the machine and to organizational norms, especially specifications of production organizations, which are consistent with the operation of machines and with improving production efficiency. Therefore, organizational norms in the business era are different from those during the days of traditional society. The major features of social organizational norms in the business era included clear relationships, obedience to authority, problem-orientation, no involvement of human feelings, impersonal and rational calculation, and so on. Organizational culture, or enterprise culture, often related to such norms. In this sense, Dr. Chen had insights into socio-cultural changes and into innovative research on the anthropological theories and methods in the business era (Chen 2003).

At the same time, researchers of the management sector have also noticed the importance of humanistic factors in management studies, and began to advocate the application of anthropological theories and methods to the research being done on management. As mentioned above, Professor Guo Yi has always advocated the humanistic spirit of management, the focus on humane care and the belief that management colleges must spread the humanistic spirit. While mentioning the localized research on management, Professor Guo Yi also makes the point that the phenomena and issues for China's organizations and management are never so-called "situational" issues, but that they are, on the contrary, issues involving independent "local knowledge" systems with certain prominent features. These features include but are not limited to the influences of local social guanxi (networks), (Guo, 2010). Some local management theorists also agree with such a view, as they believe that the development of management theories in China must focus on the specific context (Xie and Wei, 2012).

As an active advocate of humanistic values, Dr. Lv Li has focused significant attention on the application of anthropological theories and methods of management. He believes that those views advocated by anthropologists, such as cultural relativity, commonality, the adaptability of the individual to society, as well as anthropological integrity emphasized by anthropologists, all conform to the inherent characteristics of localized management practices. Therefore, it is appropriate to conduct research on management practices, especially on local management practices, with an anthropological perspective. Dr. Lv Li thus put forward the new term "management anthropology", the nature of which is 
essentially the same as the cross-disciplinary business anthropology we have been discussing. The only difference is that, according to the theory of $\mathrm{Dr}$. Lv Li, management anthropology emphasizes management practices, while the new cross-disciplinary business anthropology closely relates to economic anthropology as well as management anthropology. In addition to its focus on management practices, management anthropology also emphasizes the comprehensive consideration of product design, market promotion as well as the integration of production and sales ( $\mathrm{Lv}$, 2012 and 2009).

Although business anthropology is a new inter-disciplinary field, due to its rapid development in advanced Western market economies, there are already large quantities of research results and publications. However, in China, in the world of business administrative research, foreign publications can only provide limited reference to our present theories, since the essence of management lies in localization. The appearance of Western management theories is based on the systematic environment of the West, and is closely related to the West's political, economic, and social background. That is why combined efforts are needed from both management theorists and anthropologists for the localization of management and business anthropology.

When considering the localization path of management and business anthropology, it is necessary to mention and analyze a special case known as the " 13 Jumps" of Foxconn, which refers to the tragedy of 13 workers jumping off tall buildings in Foxconn factories between the years 2010 to 2012, because of the high pressure at work which they could not handle. At this Taiwan-funded private enterprise, beginning in 2007, employees at the company began to commit suicide frequently, drawing much public attention. "13Jumps" for a time became a buzzword in social management and business management circles in China. Why then did these tragedies occur? If we investigate the causes, it is not hard to discover that there were serious problems in the enterprise culture of Foxconn. According to anthropological theories, culture is deeply rooted in the daily life of the members of a business organization, which includes decision-making, resource allocation, position, promotion and proper behaviors. Therefore, culture affects every element of the enterprise. These elements range from job satisfaction, business turnover, productivity, profit capability and so on. It is obvious that management needed to understand the cultural variables so as to effectively improve efficiency and team cohesion.

In the case of Foxconn, the management neglected the value inherent in corporate culture, overlooking this main theme while creating the 
enterprise culture at Foxconn. This is the reason the tragedies occurred one after another. If we look at the case in a broader perspective in the localization of business administrative enterprises, we should keep in mind that China is a socialist country, and has long kept to a socialist path with Chinese characteristics. Especially after the 18th Congress of the CPC, China has been making dedicated efforts towards building the country into a moderately well-off society, with a focus on maintaining stability and harmony. If we take a look at Foxconn, we can see that it bears very strong capitalist colors, stressing only on yield, pursuing maximized profits, forcing the staff to work overtime, and never caring whether the employees could bear the pressure and stress or not. Due to their ignorance of the localized environment in a broader sense, the employees held frequent strikes, and even came to the point of committing serial suicides. In this sense, the enterprise was not stable; neither can the surrounding Chinese society remain stable, which is the opposite of the current Chinese goal of constructing a harmonious society (Tian and Dai, 2013).

In contemporary industrial society, almost every industrial organization must face the fact that their employees are of different cultural backgrounds, and such commercial companies usually need to establish a diversified team to accomplish certain specific tasks. Moreover, in such teams, mutual trust and active assistance are of great importance. In companies like Foxconn, with its founder from capitalist Taiwan, it was natural that the business had a very strong industrial and commercial background. However, its employees came from socialist mainland China, and were primarily composed of peasant workers, who carried with them a strong agricultural worldview in their job and life. Between the two cultures, there were both shared interests and some irreconcilable contradictions. The enterprise organizational culture built on shared interests is the formal cultural model of the enterprise, while a model built on cultural contradictions is the informal cultural model of the enterprise. The ethnographic research method, which enlists the expertise of anthropologists, has some fortunate advantages in studies of the differences and similarities of the formal and informal enterprise cultural models, and thus could help Foxconn solve their inherent cultural contradictions.

One of the major tasks of the 18th CPC National Congress was to make efforts to develop the cultural soft power of China, and to take the construction of cultural industry as one of the pillars in the social and economic development of China. Similarly, we believe that in the face of fierce international competition, if Chinese businesses try to succeed 
through competition, they must make efforts to create and develop the soft power of their enterprises with distinct characteristics of their own. In this sense, Chinese scholars of management science should carry out research on industrial and commercial cultures from the anthropological perspective, to plan and design enterprise culture, which will be indispensable for localized management innovation in China, and which will be of great practical significance.

\section{Conclusion}

Currently, in the community of business administration scholars, quantitative analysis still dominates. Thus, when Chinese management scholars try to provide solutions for organizational and management problems in the local culture, the first thing they think of is quantitative methodology, the approaches and methods to utilize in the study of "local knowledge" (Tian and Dai, 2013). However, they forget that cultural sources of "local knowledge" are the fundamental premises in management studies. That is, they should first understand and grasp the specific features and properties of organizational and management knowledge in terms of the national and local cultural situation in China. The largest reality facing the localization of management enterprises is the stability of the social environment, and harmony of social life, and a series of related management problems cannot be addressed through quantitative measures (Guo, 2010). Therefore, if we want to conduct business research on a more localized and diversified level, we need to advocate the application of such qualitative methods as ethnographic approaches.

Anthropology is a discipline that still needs to be developed in China, and business anthropology as a branch of applied anthropology is currently a new area yet to be explored that has a bright future (Tian and Zhou, 2012). For the management world, ethnographic research and participant observation are two specific yet related methods that are very valuable. The scientific application of such qualitative methods can provide a variety of valuable information for business administration. Through its unique yet effective approach, anthropological research methods provide a path for the study of human behavior. These methods deserve to be welcomed by the business administration world. In fact, through the visionary approach of these methods, business anthropology has already made great contributions to business research, both academically and industrially. 
The localization path of business administration in China lies in the application of anthropological research methods to local management practices, This will enable us to better understand the actual reactions to and the causes of such practices, as well as allowing us to obtain beneficial knowledge from these research methods. China, as an international global nation, is ever more actively involved in the process of globalization, and is involved with the development of its social economy. China has also specifically decided to take the development of cultural soft power as the focus of its national strategy. Research on enterprise culture has thus become more and more important. Therefore, in the future labor market in China, there will be a rapid increase in the demand for applied anthropological talents, such as business anthropologists. We have every reason to believe that business anthropology will have an important role to play in the future. We expect that research on business anthropology is to flourish and prosper through wide application and great effectiveness.

\section{References}

Alon, I. Chinese Economic Transition and International Marketing Strategy. Santa Barbara, CA: Praeger Publishers, 2003.

Anderson, K. 'Ethnographic Research: A Key to Strategy'. Harvard Business Reivew, March, 2009.

Baba, M. 'Anthropology and Business', in H. James Birx (Ed.) Encyclopedia of Anthropology. Thousand Oaks, CA: Sage Publications, 2006, pp. 83-117.

Baba, M.). 'Anthropological Practice in Business and Industry' in Kedia, S. and Willigen J. (Eds.), Applied Anthropology: Domains of Application,. Santa Barbara, CA: Greenwood Publishing Group, 2005, pp. 221-261

Bai, T., and Chen, G. 'Business Anthropology and Tourist Product Marketing', in Business Anthropology, ed. Tian, G. and Zhou, D.,. Yinchuan: Ningxia Renmin Press 2012, pp. 282-292.

Belk, R., Eileen F., and Robert K. Qualitative Consumer and Marketing Research, London: Sage Publications, 2013.

Belk, R., Sherry, J., and Wallendorf, M.'A Naturalistic Inquiry into Buyer and Seller Behavior at a Swap Meet', Journal of Consumer Research, 1989 (14): pp. 449-70.

Bruce, K. 'Henry S. Dennison, Elton Mayo and Human Relations Historiography’. Management \& Organizational History, 2006 (1): pp. 177-199. 
Burke, P. (1998) 'Anthropological Approach'. Inside Knowledge, 1998 (2): pp. 3-12.

Cayla, J., \& Eric A. 'Ethnographic Stories for Market Learning', Journal of Marketing, Vol. 77 July 2013, pp 1-16.

Cayla, J., \& Eric A. 'Stories that Deliver Business Insights' MIT Sloan Management Review, Vol.55 (Winter 2014), pp 55-62.

Chen, Y. P. (2003). 'Social Development in the Business Era and the Innovation of Chinese Anthropology Theory and Method', in Zhou, Daming and He Guoqiang (Eds.) Proceedings of Symposium on New Perspectives of Cultural Anthropology. Hong Kong International Yanhuang Culture Press, pp. 70 -78

Denny, R., \& Patricia Sunderland (forthcoming), Handbook of Anthropology in Business, Walnut Creek, CA: Left Coast Press.

Edwards, V., \& Lawrence, P. (1994) Management Change in East Germany, London and New York: Routledge.

Emery, C. R., \& Tian, R. G. (2003). 'The Effect of Cultural Differences on the Effectiveness of Advertising Appeals: A Comparison between China and the US.' Transformations in Business \& Economics. Vol.2, No.1 (3): pp. 48-59.

Emery, C. R., \& Tian, R. G. (2002). 'Cross-cultural issues in Internet marketing'. Journal of American Academy of Business, Cambridge, 12 (2): pp. 217-225.

Ferraro, G. P. The Cultural Dimension of International Business (5th Ed). Upper Saddle River, NJ: Person Prentice Hall, 2006.

Garza, C. (1991). Studying the Natives on the Shop Floor. Business Week, (9): pp. 74-78.

Gerth, K. (2010). As China Goes, So Goes the World: How Chinese Consumers Are Transforming Everything. New York, NY: Hill and Wang.

Guo Y. (2012). 'Anthropology Changes the Way of Enterprise Thinking: Human Nature to Management, Administrators, and Science of Management'. Management Experts, (12): 24-33.

- (2010). 'Localized Management Knowledge and Academic Freedom: My Perspective of Management Science in China'. Journal of Management, (4): pp. 475-488.

Gwynne, M. (2003). Applied Anthropology: A Career-Oriented Approach, Boston: Allyn \& Bacon.

Hall, E. T. (1981) The Silent Language, New York: Doubleday

Hamada, T. (1998). 'The Anthropology of Business Organization'. Anthropology of Work Review, Vol. 18 (2-3): pp 1-6. 
Hofstede, G. (1991). Cultures and Organizations: Software of the Mind, London: McGraw-Hill Book Company.

Jacoby, S. (1997). Modern Mirrors: Welfare Capitalism Since the New Deal, Princeton, NJ: Princeton University Press.

Jordan, A. (2010). 'The Importance of Business Anthropology: Its Unique Contributions'. International Journal of Business Anthropology, Vol. 1(1): pp.15-25.

-. (2003). Business Anthropology, Prospect Heights, IL: Waveland Press.

Kardiner, A., \& Preble, E. (1963). They Studied Men, New York, NY: The New American Library.

Lan, X. H., \& Tian, G. (2011a). Application of Anthropology in Business Education and the Rise of Business Anthropology. Information Management, (2): 70-75.

Lan, X. H., \& Tian, G. (2011b).' Research Methodology of Ethnography and Its Applications'. Fujian Forum, (4): 65-66.

Li, D. K. (2012). 'The Cultural Orientation of China Minority Human Resources Management'. Business Anthropology, ed. Tian, Guang and Zhou, Daming, pp. 209-223. Yinchuan: Ningxia Renmin Press.

Liu, W. R. (2012). 'The Expansion Power of Management Thought Evolution.. Management Experts, (12): pp. 34-38.

Lv, L. (2012). 'Profoundly Contextual Analysis and Interpretation: The Qualitative Method in Management Science'. Science, Management Science and Technology, (11):pp. 31-37.

-. (2009). 'Local Management Practices from the Perspective of Anthropology'. Future and Development, (8): pp. 10-13.

McCracken, G. (2009). Chief Cultural Officer: How to Create a Living, Breathing Corporation, New York: Basic Books.

Mars, G. (1994). Cheats at Work: An Anthropology of Workplace Crime, Brookfield, VT: Dartmouth Publishing Group.

Oliveira, P. (2013). People-Centered Innovation: Becoming a Practitioner in Innovation Research, Columbus, $\mathrm{OH}$ : Biblio Publishing.

Paliwoda, S. J. \& John K. R. (2008). International Business vs. International Marketing. Cheltenham, UK: Edward Elgar Publishing.

Qi, X. G., Wang, X. N., \& Liu, Z. Y. (2012). 'The Dialogue between Management Science and Anthropology'. Journal of Dalian Maritime University. (6): pp. 48-51.

Qi, X. G. (2011). 'Issues of Corporate Culture in the Context of Economic Globalization from the Perspective of Business Anthropology'. Journal of Shijiazhuang Economic University 34(4): pp. 58-61. 
Redpath, L., \& Nielsen1, M. (1997). 'A Comparison of Native Culture, Non-Native Culture and New Management Ideology'. Canadian Journal of Administrative Sciences, Vol. 14 (3): pp. 327-339

Richins, M. L. (1997). 'Measuring Emotions in the Consumption Experience'. Journal of Consumer Research, (9): pp. 127-146.

Robinson, G. M., Robinson, S., McCarthy, P. \& Oameron, C. (2010). 'Misuse of over-the-counter codeine-containing analgesics: Dependence and other adverse effects'. The New Zealand Medical Journal, 123 (1317): pp. 59-64.

Rudkin, K., \& Hemant D. (2006). 'Ethnographic Methodology and Its Implications for Banking Studies'. The Business Review: Cambridge. 6 (2): pp. 20-25.

Schwartz, P. (1991). Art of the Long View. New York, NY: Doubleday Currency.

Sherry, J., J. (1990). Marketing and Consumer Behavior: Windows of Opportunity for Anthropology, Indiana: Indiana University Press,

Squires, S, \& Bryan B, (Eds. 2002). Creating Breakthrough Ideas: The Collaboration of Anthropologists and Designers in the Product Development Industry, Westport, CT: Greenwood Publishing Group.

Strathern, M. (Ed.2000). Audit Cultures: Anthropological Studies in Accountability, Ethics, and the Academy, London: Routledge.

Tian, G., \& Dai Q. Q. (2013). 'Anthropology and Business Management: The Pathway of Localization in China'. Chinese Journal of Management, Vol. 10 (6): pp. 789-795

Tian, G., \& Zhou, D. M. (Eds. 2012). Business Anthropology, Yinchuan, Ningxia: Ningxia People's Publishing House.

Tian, R. (2010). 'The Unique Contributions and Unique Methodologies: A Concise Overview of the Applications of Business Anthropology'. International Journal of Business Anthropology, 1 (2):pp. 70-88.

Tian, R. G. (2009). 'Xinjiang and the Greater Central Asia Regional Economic Cooperation'. Journal of Applied Business and Economics, 9 (3): pp. 59-72.

Tian, R. G., Van Marrewijk A. , \& Lillis M. (2013). General Business Anthropology (2nd edition). Miami, FL: North American Business Press.

Tong C. X., \& Yan Y. J. (2011) . 'History and Importance of Anthropology in the Practice of Public Administration'. Journal of Inner Mongolia University, (3): pp. 32-37.

Walle, A. H. (2002). Exotic Visions in Marketing Theory and Practice, Westport, Connecticut: Quorum Books. 
-. (2001). Qualitative Research in Intelligence and Marketing, Westport, Connecticut: Quorum Books.

-. (2000). Rethinking Marketing, Westport, Connecticut: Quorum Books.

Wang, C. X. 2012. 'Religion and Business Operations'. Business Anthropology, ed. Tian, Guang and Zhou, Daming, pp. 224-236. Yinchuan: Ningxia Renmin Press.

Wang, J. C., \& Xu, L. (2012). 'Four Application Areas of Anthropology in Enterprise Management'. Management Experts, (12): pp. 61-65.

Xie P. H., \& Wei N. J. (2012). ,Explore the Localized Path of Management by the Chinese Scholars,. Journal of Management, (9): pp. 1262-2155.

Yucel, R., Elibol, H., \& Dagdelen, O. (2009). 'Globalization and International Marketing Ethics Problems'. International Research Journal of Finance and Economics, (26): pp. 93-104.

Zhou, D. \& Sun, C. (2009). 'Group Differences among Nongmingong: A Follow-up Ethnographic Case Study'. International Journal of Business Anthropology 1(1): pp. 79-94. 
